\title{
¿Abandono planificado? Restos forestales carbonizados en sitios arqueológicos de La Ciénaga (Catamarca, Argentina)
}

Abandon planifié? Vestiges de forêts carbonisés du site archéologique de La

Ciénaga (Catamarca, Argentine)

Planned abandonment? Charcoal remains from archaeological sites in La

Cienaga, Catamarca, Argentina

\section{María Celeste Valencia y Bárbara Balesta}

\section{OpenEdition \\ Journals}

Edición electrónica

URL: http://journals.openedition.org/bifea/4031

DOI: 10.4000/bifea.4031

ISSN: 2076-5827

Editor

Institut Français d'Études Andines

Edición impresa

Fecha de publicación: 1 agosto 2013

Paginación: 145-172

ISSN: 0303-7495

Referencia electrónica

María Celeste Valencia y Bárbara Balesta, « ¿Abandono planificado? Restos forestales carbonizados en sitios arqueológicos de La Ciénaga (Catamarca, Argentina) », Bulletin de l'Institut français d'études andines [En línea], 42 (2) | 2013, Publicado el 08 agosto 2013, consultado el 05 noviembre 2020. URL http://journals.openedition.org/bifea/4031 ; DOI : https://doi.org/10.4000/bifea.4031

\section{(c) $($ () $\ominus$}

Les contenus du Bulletin de l'Institut français d'études andines sont mis à disposition selon les termes de la licence Creative Commons Attribution - Pas d'Utilisation Commerciale - Pas de Modification 4.0 International. 


\title{
¿Abandono planificado? Restos forestales carbonizados en sitios arqueológicos de La Ciénaga (Catamarca, Argentina)
}

\author{
María Celeste Valencia* \\ Bárbara Balesta**
}

\section{Resumen}

En el presente texto se comentan los resultados de las excavaciones llevadas a cabo en dos sitios arqueológicos del valle de Hualfín (Catamarca. Argentina), ocupados durante el siglo XV. En los mismos se han obtenido evidencias de grandes incendios, consistentes en abundante material de origen vegetal, usado en la construcción de estructuras de vivienda. Los estudios realizados sobre los restos forestales hallados en el interior de las mismas, su localización y relación con otros componentes del registro (cerámica, hueso y marlos) y la comparación con otros sitios nos permiten realizar interpretaciones sobre el conocimiento de los habitantes de la zona respecto de las características técnicas de las maderas, su uso para cumplir funciones estructurales en la construcción y establecer relaciones entre los contextos de hallazgo y posibles eventos de abandono.

Palabras clave: restos forestales, incendios, abandono, arqueología argentina, Catamarca

\section{Abandon planifié ? Vestiges de forêts carbonisés du site archéologique de La Ciénaga (Catamarca, Argentine)}

\section{Résumé}

Ce travail analyse les résultats des fouilles effectuées sur deux sites archéologiques de la vallée de Hualfín (Catamarca, Argentine), occupés au XVe siècle. On y a trouvé des preuves d'incendies importants, sous forme de matière végétale abondante, utilisée dans la construction de structures d'habitat. Les études sur les restes végétaux trouvés à l'intérieur des maisons, leur emplacement et leur 
relation avec les autres éléments enregistrés (poterie, os, épis), ainsi que la comparaison avec d'autres sites nous permettent de faire des interprétations sur la connaissance des habitants concernant les caractéristiques techniques du bois, leur utilisation destinée à remplir des fonctions structurelles dans la construction et l'établissement de relations entre les contextes de découverte et d'éventuels abandons.

Mots clés: vestiges de forêts, incendies, abandon, archéologie argentine, Catamarca

\title{
Planned abandonment? Charcoal remains from archaeological sites in La Cienaga, Catamarca, Argentina
}

\begin{abstract}
We analyzed two archaeological sites occupied during the fifteenth century A.D., located in the Hualfín Valley (Catamarca. Argentina). Excavations in these sites provided evidence of massive fires. We studied the specific characteristics of charcoal deposits including their locations and relationships to other materials (pottery, bone, charred maize) and we compared the results with finds from other sites. In this paper we focus on the inhabitant's knowledge relating to forest resources and the technical condition of timbers and other building materials. Prosopis and Geoffrea specimens are identified as part of roof structures. Evidence of the fires is related to site's abandonment.
\end{abstract}

Key words: forest remains, fires, abandonment, Argentine archaeology, Catamarca

\section{INTRODUCCIÓN}

Este artículo analiza materiales antracológicos provenientes de excavaciones de habitaciones en sitios adscritos al Período de Desarrollos Regionales/Inka (sensu Núñez Regueiro, 1974) en el valle de Hualfín del noroeste argentino (en adelante NOA).

El Período de Desarrollos Regionales tuvo lugar en dicha área entre 1000 y 1450 A.D. y se caracterizó por un incremento agrícola a través de la implementación de sistemas de irrigación artificiales y el uso intensivo de las tierras. Esto permitió un crecimiento demográfico y concentración de poblaciones, con la necesidad de implementar organizaciones políticas más complejas que en períodos anteriores.

Algunos autores han planteado que durante esta época, como consecuencia del aumento demográfico, del desarrollo de la territorialidad y posiblemente de un cambio climático (v.g. sequías extremas en vastas regiones del altiplano) que generó una presión poblacional hacia los valles mesotérmicos (Nielsen, 2002; Rothhammer \& Santoro 2001), cobra importancia la guerra por la exclusividad en la explotación de nichos ecológicos. Aparecen las fortificaciones, que pueden haber cumplido un rol importante como respuesta defensiva a las presiones y ataques de los grupos nómadas y seminómadas del oriente (González, 1979; Núñez Regueiro, 1974). 
A partir de la segunda mitad del siglo XV gran parte del NOA fue incorporado al Tawantinsuyu. A raíz de dicha anexión, parte de las evidencias arqueológicas muestran modificaciones en los modos de vida locales. Así como se ha registrado en otras regiones, el dominio inkaico cultivó estrategias particulares para cada caso, tanto en lo concerniente a la explotación de recursos y mano de obra como en cuanto a las características geográficas y el desarrollo político de cada pueblo. El NOA fue incorporado a la red vial inkaica y a lo largo de la misma establecieron guarniciones militares, centros administrativos y de almacenamiento; algunos de estos centros también fueron productores de bienes artesanales. Asimismo, los inkas se establecieron sobre poblados preexistentes.

En el valle de Hualfín, ubicado en el centro de la provincia de Catamarca (fig. 1), el Período de Desarrollos Regionales se manifestó a través de los grupos portadores de la que en la arqueología clásica fue denominada como «Cultura Belén»1.

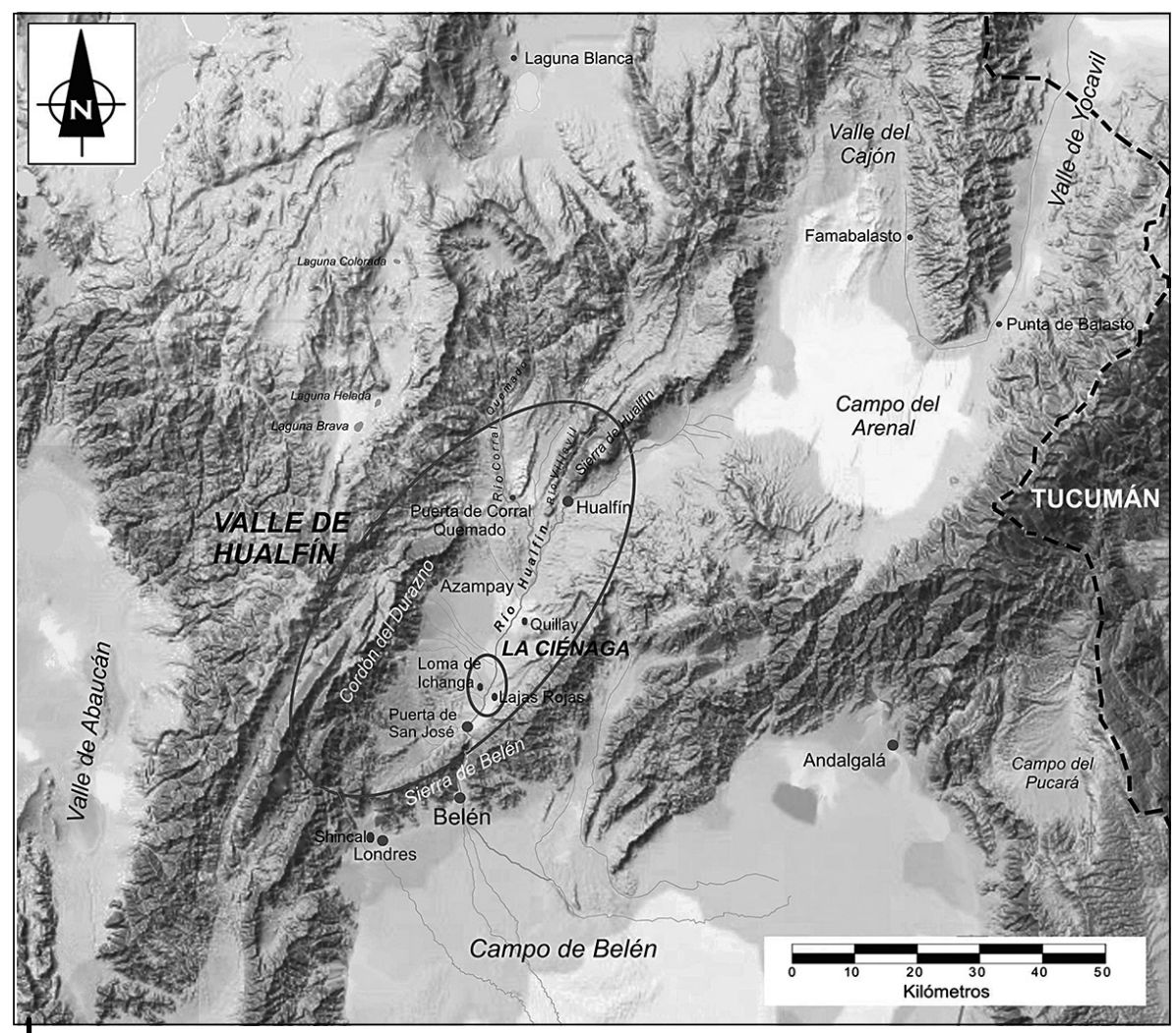

Figura 1 - Mapa del valle de Hualfín con los sitios mencionados

1 Uno de los indicadores más utilizados para reconocer la presencia de la «cultura Belén» ha sido la cerámica Belén, que incluye tinajas y cuencos pintados en negro sobre un baño rojo. 
Gran parte de los sitios de habitación se localizaron sobre lomadas de difícil acceso, protegidas en muchos casos por murallas defensivas, con diferentes cantidades de recintos así como distintos grados de aglomeración. Por otra parte, existen sitios contemporáneos, conformados por estructuras dispersas, emplazadas entre los campos de cultivo, sobre el piedemonte que desciende de la ladera occidental del valle. En las ocupaciones se ha hallado cerámica Belén, cerámica ordinaria con evidencias de uso y en menores proporciones, cerámica adjudicada a otros grupos que habitaban áreas vecinas (Santa María, Sanagasta y Famabalasto Negro Grabado); puntas de proyectil de obsidiana y hueso, objetos líticos de molienda, restos arqueofaunísticos (camélidos, cérvidos, felinos, roedores), cuentas de malaquita, objetos de metal, restos vegetales (postes y vainas de algarrobo, semillas de maní, marlos de maíz, etc.) y en algunos de ellos, evidencias de incendios masivos vinculadas a condiciones de abandono de los sitios (González \& Pérez, 1968; Wynveldt, 2007; Wynveldt \& Balesta, 2009; Balesta \& Zagorodny, 2010).

El estudio que aquí se propone, concierne especialmente a los restos materiales de incendios recuperados en los sitios Loma de Ichanga y Lajas Rojas 4, de la localidad de La Ciénaga (fig. 1); por una parte, para dilucidar el conocimiento de los pobladores sobre las diferentes especies forestales y los diversos usos a los que las destinaron. Por otra parte, se analiza la localización de los materiales carbonizados, sus condiciones sanitarias y de depositación y se compara con información similar de otras excavaciones en el valle de Hualfín, a fin de vincular los hallazgos con la modalidad de abandono de los sitios.

La relevancia del estudio radica en aportar información para la identificación de modalidades y causas posibles de abandono en el contexto de beligerancia propuesto para este período en el valle de Hualfín.

\section{EL AMBIENTE EN LA ZONA DE ESTUDIO, LOS RECURSOS MADERABLES Y SUS CARACTERÍSTICAS}

El valle de Hualfín, en el centro de la provincia de Catamarca (Argentina); corresponde al área surcada por el río Hualfín y sus afluentes (fig. 1).

Desde el punto de vista fitogeográfico el área pertenece a la Región Neotropical, dominio Chaqueño, Provincia de Monte (Cabrera, 1976; Morlans, 1995), donde predomina el matorral o la estepa arbustiva xerófila, sammófila o halófila (Cabrera, 1976). Tortorelli (1956) denomina a esta zona «Monte Occidental» y la describe como una formación arbustiva de características xerófilas, en la que suelen presentarse algunos árboles de escasa magnitud y fuste. La zona se extiende sobre una extensa planicie, con ondulaciones que se acentúan hacia el oeste y en las cercanías de la precordillera andina.

La región es semiárida y de clima subtropical con una temperatura media anual de $20^{\circ}$ C, registrándose temperaturas de hasta 45으 C en verano. La precipitación es de 200 a 400 mm anuales y las Iluvias ocurren principalmente en verano. Los suelos predominantes en los valles y bolsones son muy susceptibles a la erosión eólica, 
con muy baja capacidad de retención de agua y escaso contenido de materia orgánica. Esto, sumado a las altas temperaturas y la elevada evapotranspiración que sufren las plantas, favorece el desarrollo de especímenes capaces de soportar largos períodos de sequía. En los fondos de los valles se forman galerías, en donde se observa un amplio predominio de especies del género Prosopis sp L. Fabácea. Las áreas de transición o intermedias se encuentran cubiertas por una formación de tipo estepa arbustiva xerófila baja y rala.

La vegetación leñosa nativa (cuadro 1) está constituida por arbustos espinosos y de porte tortuoso. Abundan representantes de las zigofiláceas en varias especies del género Larrea sp. Zygophillacea, Ilamadas vulgarmente «jarillas»; hay además numerosas leguminosas del género Prosopis.

Cuadro 1 - Listado de la vegetación leñosa nativa actual

\begin{tabular}{lcc}
\hline \multicolumn{1}{c}{ Nombre científico } & Familia & Nombre vulgar \\
\hline Acacia caven (Molina) Molina & Fabáceae & $\begin{array}{c}\text { curqui, espino, } \\
\text { espinillo }\end{array}$ \\
Adesmia trijuga. Gillies ex Hook. \& Arn & Fabáceae & cuerno de cabra \\
$\begin{array}{l}\text { Bulnesia retama (Gillies ex Hook. \& Arn). } \\
\text { Griseb. }\end{array}$ & Zygophillaceae & retamo \\
Condalia microphyla (Reissek) & Rhamnaceae. & piquillín \\
Larrea cuneifolia. Cav. & Zygophillaceae & jarilla \\
Larrea divaricata. Cav. & Zygophillaceae & jarilla \\
Larrea nítida.Cav. & Zygophillaceae \\
$\begin{array}{l}\text { Plectrocarpa tetracantha.Gillies ex Hook. } \\
\text { \& Arn }\end{array}$ & Zygophillaceae \\
$\begin{array}{l}\text { Plectrocarpa rougessi.Descole, O’Donell } \\
\text { \& Lourteig }\end{array}$ & Zygophillaceae & radajillo \\
$\begin{array}{l}\text { Prosopis torcuata (Cav. ex Lag.) DC. } \\
\text { Senna aphylla (Cav.) H. S. Irwin et }\end{array}$ & Fabáceae & entetaco, tintitaco \\
Barneby & Fabáceae & pichana \\
Suaeda divaricata Moq. & Chenopodiaceae \\
Trichocereus atacamensis (Phil.) Backeb & Cactaceae & vidriera \\
Zuccagnia puntacta Cav. & Fabaceae & pupo, pus pus \\
\hline
\end{tabular}

Las especies arbóreas nativas (cuadro 2) se hallan muy diseminadas, disponiendo de gran espacio, presentando fustes cortos y copas amplias, ramificadas y típicamente globosas o aparasoladas (Tortorelli, 1956). 
Cuadro 2 - Listado de las especies nativas arbóreas actuales

\begin{tabular}{|c|c|c|}
\hline Nombre científico & Familia & Nobre vulgar \\
\hline Acacia visco. Lorentz ex Griseb. & Fabácea & viscote \\
\hline Acacia caven (Mol) Mol. & Fabaceae & espinillo, churqui \\
\hline Cercidium praecox, (Ruiz et Pavon) Burkart. & Cesalpinaceae & brea, palo verde. \\
\hline $\begin{array}{l}\text { Geoffroea decorticans (Gillies ex Hook. \& } \\
\text { Arn.) Burkart. }\end{array}$ & Fabaceae & chañar \\
\hline Lithraea molleoides (Vell.) Engl. & Anacardiaceae & molle dulce \\
\hline Populus alba L. & Salicaceae & álamo \\
\hline Populus nigra L. & Salicaceae & álamo \\
\hline Prosopis alba, Griseb. & Fabaceae & $\begin{array}{c}\text { Algarrobo blanco, el } \\
\text { árbol }\end{array}$ \\
\hline $\begin{array}{l}\text { Prosopis Chilensis (Molina) Stuntz emend. } \\
\text { Burkart, }\end{array}$ & Fabaceae & $\begin{array}{l}\text { Algarrobo chileno, el } \\
\text { árbol }\end{array}$ \\
\hline Prosopis flexuosa DC. & Fabaceae & Algarrobo, el árbol \\
\hline Prosopis nigra, (Griseb.) Hieron & Fabáceae & $\begin{array}{l}\text { Algarrobo negro, el } \\
\text { árbol }\end{array}$ \\
\hline Schinus areira, L. & Anacardiaceae & molle \\
\hline $\begin{array}{l}\text { Trichocereus terscheckii (Parm. ex Pfeiff) } \\
\text { Britton et Rose }\end{array}$ & Cactácea & cardón \\
\hline
\end{tabular}

A fin de evaluar las posibles aplicaciones de las especies leñosas más utilizadas en la zona, creemos relevante presentar algunas de sus características técnicas y físico-mecánicas.

La madera de Prosopis es dura, pesada e impermeable; presenta aptitud para fines constructivos y como carbón y leña. Si bien Prosopis flexuosa alcanza alturas entre 5 y 7 m en zonas abiertas y Prosopis chilensis puede llegar hasta 9 y $10 \mathrm{~m}$ en las riberas de cursos de agua (Capparelli et al., 2003), la altura utilizada para postes en estas especies es de 2 a $3 \mathrm{~m}$. Esto se debe a que, a partir de ese rango, los troncos se dividen en dos o más ramas; por lo tanto, se suelen cortar a dicha altura, dejando una porción de dos ramas en el extremo, que constituyen el soporte de las vigas.

Para el género Prosopis se ha registrado una disminución en su uso a través del tiempo, probablemente debido a la reducción de su tasa de disponibilidad (Ifona, 1985). Sin embargo, el Ifona (1985) ha documentado su utilización para toda la provincia de Catamarca, tanto para combustible como para la fabricación de postes de viviendas. 
Con respecto a otros géneros aptos para la construcción presentes en el valle, se puede señalar al chañar, Geoffroea decorticans (Gill. ex Hook. \& Arn.) Burkart. Fabácea, que posee una madera medianamente pesada, con aptitud para la construcción y combustible. Tiene un fuste erguido cuando crece aislado, pero es arbustivo cuando se desarrolla en bosquecillos. Mide entre 3 y $10 \mathrm{~m}$ de altura y tiene un tronco que no supera los $40 \mathrm{~cm}$ de diámetro; la corteza se desprende longitudinalmente en fajas irregulares por debajo de las cuales aparece una nueva corteza verde.

Acacia visco Lorentz ex Griseb. Fabácea es otra especie autóctona del noroeste argentino. El árbol es de mediano porte, su follaje es caduco y puede alcanzar hasta $12 \mathrm{~m}$ de altura, unos $50 \mathrm{~cm}$ de diámetro de fuste, con tronco erecto o inclinado. Es una especie de rápido crecimiento, muy rústica, poco exigente en suelo y resistente a la sequía y salinidad. Produce madera de buena calidad, dura, pesada y muy densa, que puede ser usada para postes, leña y carbón. Tales características la hacen útil para su empleo en la fabricación de durmientes y carpintería en general y también se utiliza como combustible. Hemos observado la utilización de ramas pequeñas de Acacia visco (15 a 20 mm de diámetro) para la confección de las enramadas (Valencia et al., 2010).

Trichocereus terscheckii (Parm. ex Pfeiff) Britton et Rose. Cactácea ocupa un lugar importante en el paisaje del NOA y también en la vida de sus habitantes. Suele ocupar laderas rocosas, semiplanicies y planicies. Es una planta muy utilizada localmente tanto por su madera como por sus frutos y espinas. Según nuestras observaciones y de otros autores, su madera es empleada para la confección de puertas, dinteles y vigas (Capparelli \& Raffino, 1997).

El género Populus sp. es alóctono, estos árboles son originarios del hemisferio norte; es una especie de rápido crecimiento y de fuste erecto. Presenta un comportamiento mecánico con resistencias muy bajas, lo cual asociado a su baja densidad hace que sus potencialidades constructivas estén acotadas a construcciones ligeras. Sin embargo, hemos observado la utilización de este género en la construcción de las viviendas actuales para la confección de vigas y postes portantes.

\section{REGISTRO DE MODALIDADES CONSTRUCTIVAS TRADICIONALES EN EL VALLE DE HUALFÍN}

La observación de los modos constructivos de las viviendas tradicionales nos ha permitido realizar interpretaciones acerca de la ubicación y características de los materiales leñosos hallados en los sitios arqueológicos.

Las modalidades implementadas en este tipo de viviendas han sido recuperadas por nosotros sobre la base de observación etnográfica sistemática y entrevistas a informantes clave.

En algunas de las viviendas construidas de este modo aún viven familias, mientras que otras se encuentran deshabitadas; no obstante, parientes de los antiguos 
habitantes las visitan periódicamente y las utilizan con diversos fines (para guardar pertenencias, para descansar mientras desarrollan actividades tales como el pastoreo o la siembra), ejerciendo derechos de propiedad sobre las mismas (Balesta et al., 2005; Valencia et al., 2009; Valencia, et al., 2010).

El registro realizado permite caracterizar estas construcciones a través de la utilización de paredes de adobe y/o piedra; techo a una o dos aguas, sustentado por varios postes de madera que exhiben una bifurcación — denominados en la zona como «horcones»-, los cuales portan vigas de troncos de menor diámetro. Sobre ellas se apoya una trama compacta de ramas alineadas una al lado de otra — llamada «enramada»_ y por encima de ellas se coloca un amasado de arcilla y agua que contiene mezclado un material vegetal muy fino al que nombran como «torta del techo» (fig. 2).

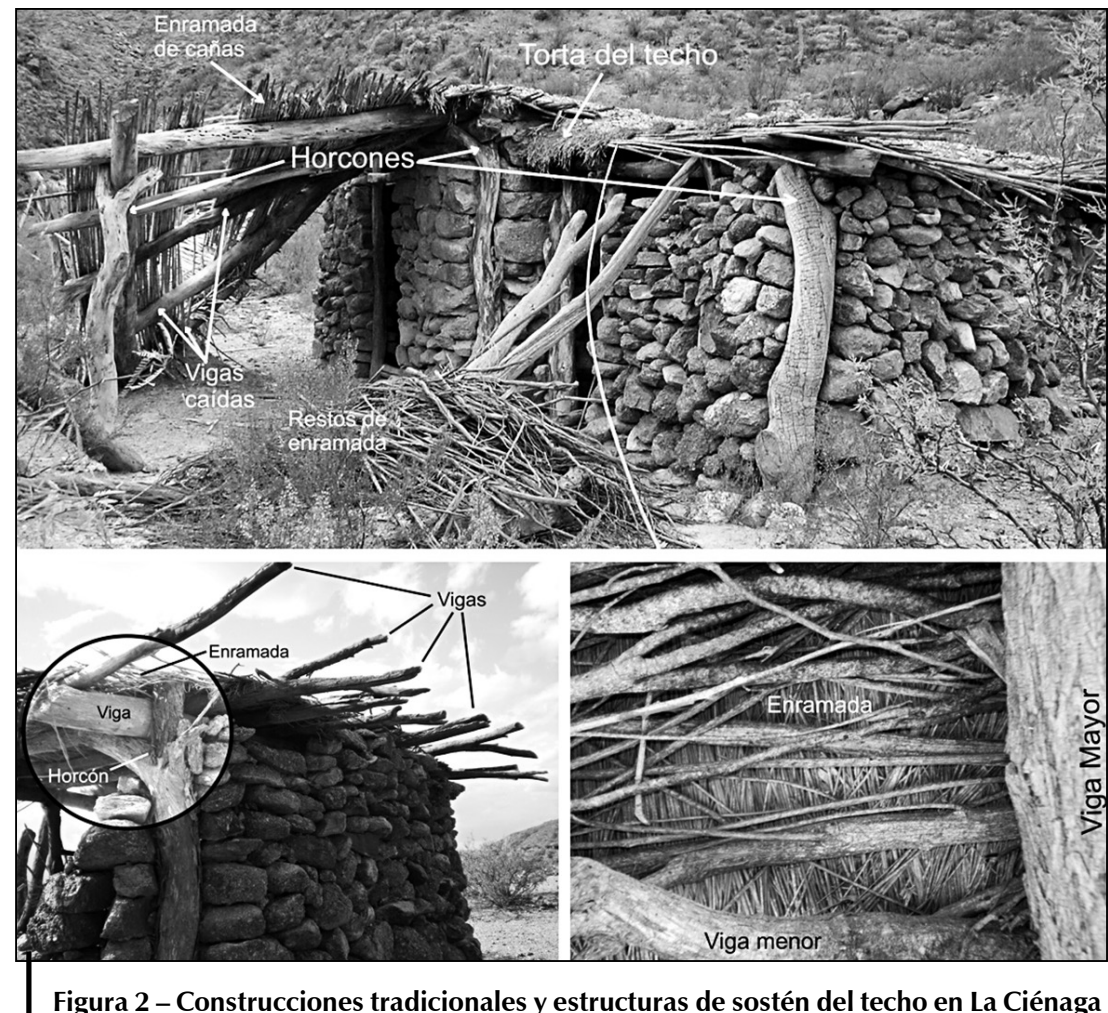

Los postes de sostén se colocan generalmente fuera de las estructuras, en los cuatro ángulos de las mismas; aunque pueden existir también postes internos, ubicados tanto en el centro de las estructuras como en los ángulos. Las vigas se colocan alineadas dentro y/o fuera de las habitaciones, variando su número de acuerdo con el tamaño de las mismas, pudiendo encontrarse de dos a tres unidades en estructuras con 3 a 5 m de longitud (fig. 2) 
En la actualidad los postes que sostienen los techos habitualmente son confeccionados con Populus sp. L. Salicácea, al igual que las vigas. La incorporación de Populus sp. constituye una innovación constructiva, introducida en la zona a partir de los siglos XVIII y XIX.

No obstante, hemos registrado la utilización de madera de Prosopis sp. para postes de sostén tanto en casas tradicionales que han sido abandonadas como en otras que actualmente siguen en uso y cuya estructura de techos tiene más de cincuenta años. Los informantes relatan que la parte de los postes de sostén que estaba en contacto con el suelo solía pudrirse, por lo cual se acostumbraba cortar la parte dañada y seguir utilizando el poste mientras este estuviera en condiciones de resistir el peso del resto del techo.

Asimismo, hemos observado etnográficamente la utilización de Trichocereus terscheckii Cactácea para fabricar vigas y dinteles, lo cual no ha sido corroborado en el registro arqueológico de los sitios excavados por nosotros en el valle de Hualfín.

En cuanto a la construcción de la enramada, actualmente se utiliza mayormente caña pero también se recurre al «pupo» (Zuccagnia punctacta Cav.) que, debido a la alta cantidad de resinas presentes en sus tallos, posee una elevada resistencia a insectos, hongos y humedad. Las casas tradicionales solían utilizar también «Cortadera» (Cortadeira selloana (Schult. \& Schult.f.) Asch. \& Graebn.) para estos fines, pero en menor medida debido a que, según comentan los pobladores locales, «atrae muchos bichos».

\section{LOS SITIOS ESTUDIADOS}

Hacia el margen occidental del río Hualfín se ubican asentamientos adscritos al período de Desarrollos Regionales. Algunos se hallan emplazados sobre lomadas o mesetas bajas, correspondientes a los depósitos de piedemonte que descienden desde la cadena occidental de los cerros, mientras que otros se ubican sobre las pequeñas terrazas formadas por los ríos que discurren hacia el Hualfín. Estos cauces, de curso estacional, permanecen secos durante todo el año y solo transportan agua en cortos y drásticos eventos de precipitaciones durante el verano.

En la confluencia de los ríos Ichanga y La Calera —ambos de curso transitorio-, se halla la Loma de Ichanga ${ }^{2}$, a unos 1515 msnm, localizada sobre una lomada plana, con una altura de 50 m (Balesta \& Wynveldt, 2010). El ascenso se lleva a cabo por una senda muy empinada, ubicada en el extremo oriental de la lomada, donde confluyen ambos ríos. Las laderas hacia el oeste y noroeste son inaccesibles. En su cima se hallan quince recintos de piedra de forma cuadrangular.

En las proximidades de la senda de acceso actual se observa un sector de mayor concentración conformado por diez estructuras (fig. 3), mientras que los otros 
cinco recintos se ubican más dispersos. En todo el sitio se registran solo dos estructuras agrupadas (recintos 6 y 7 ) a las cuales se ha denominado conjunto 1; el resto de las estructuras se encuentran aisladas.

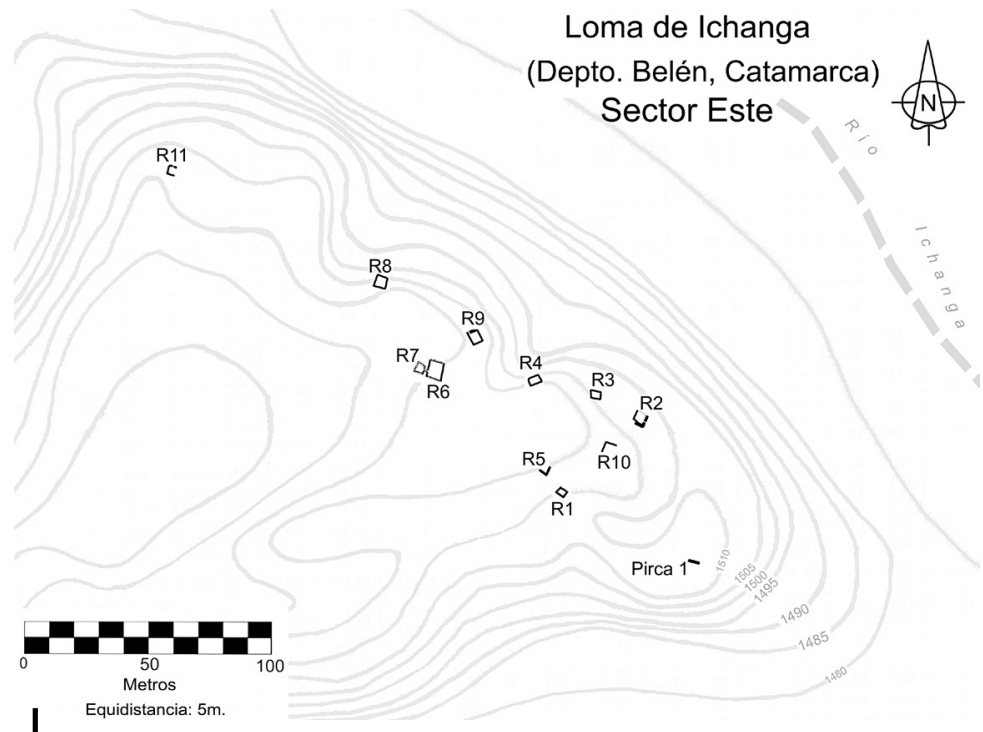

Figura 3 - Plano del sector concentrado de la Loma de Ichanga

La mayor parte de las paredes de los recintos son simples, construidas con bloques irregulares de granito y lajas metamórficas, todos presentes en la cima del sitio; corresponden a rodados y bloques de diversos tamaños, que forman parte de los depósitos del piedemonte occidental del valle. Se han registrado, asimismo, paredes dobles rellenas con ripio, con aberturas y largos pasillos de acceso (Balesta \& Wynveldt, 2010).

Los sitios que se encuentran ubicados en la margen oriental del río Hualfín se emplazan sobre las estribaciones de la sierra de Belén y en las terrazas del río. La terraza de la margen oriental del Hualfín es plana y va variando su altura respecto al río, con un máximo de $8 \mathrm{~m}$ aproximadamente, mientras que en los sectores donde se observan derrumbes no supera el metro de altura. En general es continua, exceptuando una depresión en el sector central, en la que se produjo el derrumbe de los diferentes estratos (Alosilla et al., 2006; Valencia et al., 2010). Hacia el este comienza a elevarse hasta empezar a formar los primeros espolones del Cerro Colorado ${ }^{3}$. Sobre el mismo se emplaza un sitio fortificado que contiene más de 100 estructuras de paredes de piedra y próximas al pie del cerro se encuentran otras estructuras. Se trata de hiladas de piedras canteadas que forman 
habitaciones rectangulares aisladas, cercanas a dos cistas funerarias, también saqueadas. Los conjuntos que presentan estas características fueron denominados Lajas Rojas. Hasta el momento se han identificado cuatro estructuras de este tipo, de las cuales se han excavado tres. Presentan planta rectangular, con paredes de aproximadamente 3 a $5 \mathrm{~m}$ de longitud, todas construidas con piedras de coloración rojiza.

\section{LAS EXCAVACIONES EN LOMA DE ICHANGA}

En el año 2007 se excavaron los recintos 6 y 7 que configuran el único agrupamiento de estructuras dentro del sitio (fig. 4). Este conjunto se halla ubicado a un lado de una pequeña cárcava con una pendiente que desciende de oeste a este y que probablemente atravesaba el recinto 7. Esta situación habría llevado a nivelar dicho recinto y construir la pared en dirección este-sudeste como un muro de contención en el que ubicaron grandes lajas paradas con el objetivo de evitar derrumbes.

El recinto 6 presenta dimensiones de aproximadamente 4 por $4 \mathrm{~m}$; sus paredes sudoeste, noroeste y noreste están formadas por una hilada de piedras en terraplén, mientras que la pared sudeste presenta dos hileras de piedra con relleno de tierra de 1,5 $\mathrm{m}$ de ancho. Esta última pared contiene un pasillo de 0,6 $\mathrm{m}$ de ancho que comunica ambos recintos.

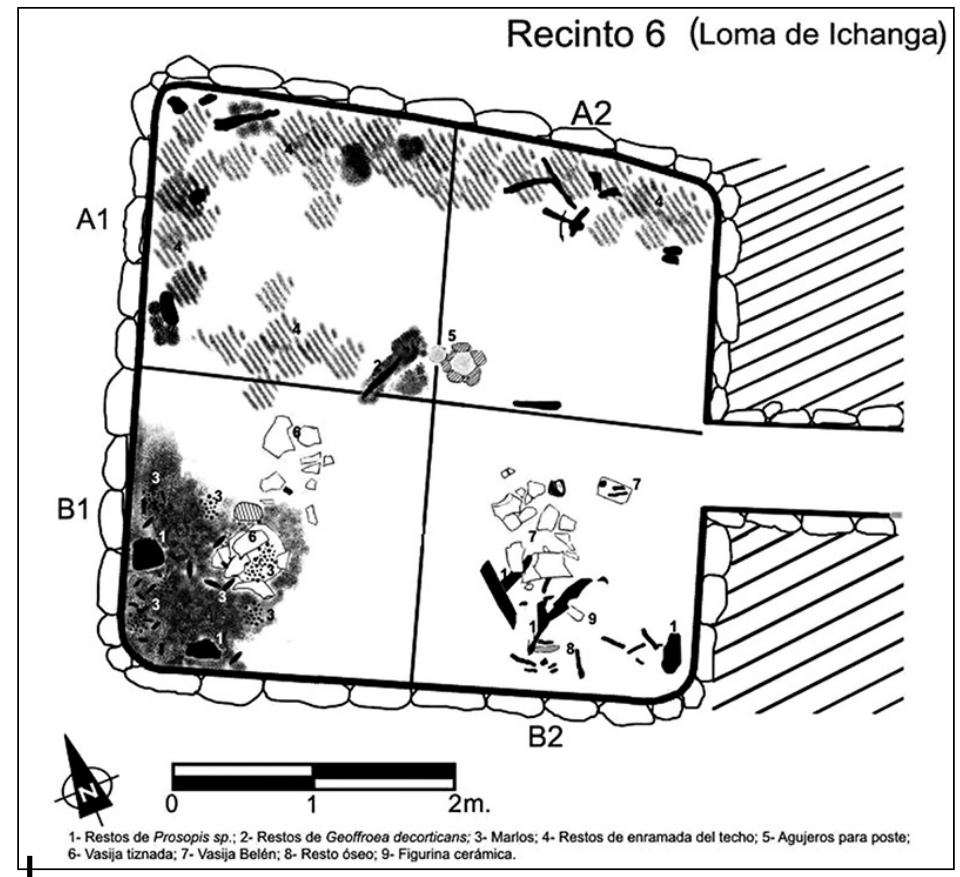

Figura 4 - Plano de las excavaciones del recinto 6 de Loma de Ichanga 
La excavación del recinto 6 (fig. 4) implicó su división en cuatro cuadrículas, denominadas A1, A2, B1 y B2 y se desarrolló según la técnica de décapage, en niveles artificiales de $10 \mathrm{~cm}$. Se puede describir a grandes rasgos diciendo que comprendió dos estratos de unos $40 \mathrm{~cm}$ cada uno y el piso. El primer estrato abarca los $40 \mathrm{~cm}$ iniciales desde la superficie y en él se hallaron piedras, producto del derrumbe de las paredes y raíces de vegetación actual. El segundo estrato comprende desde los $40 \mathrm{~cm}$ hasta los $80 \mathrm{~cm}$ de profundidad. A partir de los $40 \mathrm{~cm}$, en la cuadrícula B1 se descubrieron los restos de dos postes. Por debajo del poste localizado sobre la pared noroeste se observó una concentración de marlos de maíz ${ }^{4}$, mientras que en las cuadrículas restantes del mismo estrato, se recuperaron restos de postes, vigas, enramada y torta del techo.

Los restos de postes y marlos en la cuadrícula B1 aparecieron hasta aproximadamente los $70 \mathrm{~cm}$, profundidad en la que se hallaron varios fragmentos cerámicos (fig. 4). Los mismos fueron remontados hasta reconstruir, en forma parcial, una vasija que presentaba hollín en su interior, pintada en negro sobre crema; de acuerdo con su morfología globular y características decorativas puede adjudicarse a los denominados tipos Sanagasta 5 . En ese mismo nivel, en la cuadrícula B2, se exhumaron restos de una tinaja Belén que fue reconstruida casi totalmente y próximos a la pared sur se recuperaron un fragmento óseo calcinado y una figurina de cerámica que presentaba la cabeza rota.

El piso del recinto se halló a los $80 \mathrm{~cm}$, donde se manifestó una gran dispersión de restos de postes y vigas; en el centro de la estructura se identificaron dos círculos revestidos con piedras, con diámetros de 10 y $18 \mathrm{~cm}$, interpretados como agujeros para el poste central de sostén del techo (fig. 5).

En la excavación del pasillo que comunica ambos recintos solo se hallaron unos pocos fragmentos cerámicos, partículas de carbón y piedras producto del derrumbe de las paredes adyacentes.

El recinto 7 fue excavado parcialmente (cuadrículas A1 a A6 y B1 a B5), presentando unas dimensiones aproximadas de 6 por $7 \mathrm{~m}$. Sus paredes, a excepción del tramo asociado al recinto 6 , son de una sola hilada de piedras. En este recinto disminuyeron notablemente los hallazgos así como la potencia del sedimento. Se excavaron $30 \mathrm{~cm}$ hasta

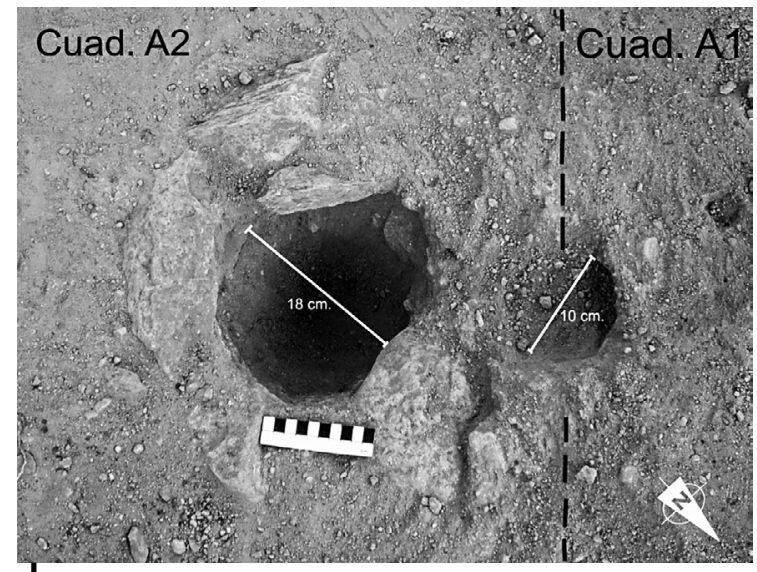

Figura 5 - Agujeros para poste en recinto 6 de Loma de Ichanga

4 Se denomina marlo al corazón de la mazorca de maíz.

5 La cerámica Sanagasta comprende vasijas de gran tamaño y paredes gruesas, con decoración geométrica en negro sobre un baño crema o rojo, cuyo origen ha sido ubicado en las provincias de La Rioja y San Juan, en el mismo período aquí tratado. 
alcanzar el piso, sobre el que se recuperaron fragmentos de un cuenco Belén que fue reconstruido parcialmente.

Sobre uno de los marlos extraídos del recinto 6 (cuadrícula B1, por debajo de los 40 cm), se realizó un fechado radiocarbónico 6 cuya interpretación, a la luz del registro, promueve su datación dentro de la segunda mitad del siglo XV de nuestra era.

\section{LAS EXCAVACIONES EN LAJAS ROJAS 4}

El recinto 4 de Lajas Rojas se encuentra situado en el sector norte de la terraza oriental, al pie del Cerro Colorado. Este recinto tiene forma rectangular y mide aproximadamente unos 5 por $3 \mathrm{~m}$; presenta paredes manufacturadas con bloques de arenisca rojiza dispuestos en hiladas, conformando muros simples.

Los trabajos comenzaron con la división del recinto en cuatro cuadrículas denominadas A1, A2, B1 y B2 (fig. 6).

En la excavación se utilizó la misma técnica que en Loma de Ichanga. La pared este, que se había registrado claramente durante la prospección realizada en campañas anteriores, no se observaba al principio de la excavación por hallarse debajo de una elevación de tierra, producto de derrumbe. Aproximadamente a los $45 \mathrm{~cm}$ de profundidad se visualizó esta pared, por lo cual se abrieron dos nuevas cuadrículas (A3 y B3). Para fines descriptivos la excavación se puede dividir en lo que se ha considerado tres estratos y el piso. En el primer estrato — desde la superficie a los $20 \mathrm{~cm}$ - se hallaron raíces de vegetación actual (Larrea sp., Opuntia sp.). El segundo, entre los 20 y $40 \mathrm{~cm}$, presenta materiales dispersos en el sedimento (pequeños trozos de carbón, un resto óseo y algunos tiestos cerámicos). El tercer estrato se encuentra entre los 40 y $80 \mathrm{~cm}$ de profundidad, donde se observan, en estratigrafía, algunas piedras entremezcladas con restos de techo representados por ramas y vestigios de enramada. Por debajo se halló una horqueta y vigas, las cuales estaban depositadas directamente sobre el piso de la estructura. En este último estrato aparecieron fragmentos de cerámica.

En A1 entre 40 y $50 \mathrm{~cm}$ se recuperaron marlos entremezclados con piedras, raíces de jarilla (Larrea sp.), y ramas carbonizadas que corresponden a la enramada de techo. También en esta cuadrícula y nivel, sobre la pared oeste, se hallaron ramas carbonizadas entremezcladas con piedras, las cuales pueden haber caído encima como producto del derrumbe de la pared o bien haber estado depositadas sobre la enramada, lo cual constituye una práctica habitual, según hemos observado etnográficamente. En el centro de la cuadrícula A1, en el nivel 50-60 cm se distinguen dos troncos ubicados en forma paralela muy próximos entre sí y orientados en sentido nor-noroeste/sur-sudeste junto a restos de enramada.

6 El fechado radiocarbónico sobre uno de los marlos arrojó un resultado de $420 \pm 50$ años AP (LP$1832 ;{ }^{13} \mathrm{C} /{ }^{12} \mathrm{C}=-10 \pm 2 \%$ ), cuya calibración para 1 sigma dio un rango entre 1449-1621 cal DC., de acuerdo a la curva SHcal04 (McCormac et al., 2004) con el Programa Calib Rev 5.0.1. Las probabilidades dentro de dicho rango indican una proporción de 0,63 para el subrango 1449-1510 cal DC. y de 0,37 para 1577-1621 cal. DC. 


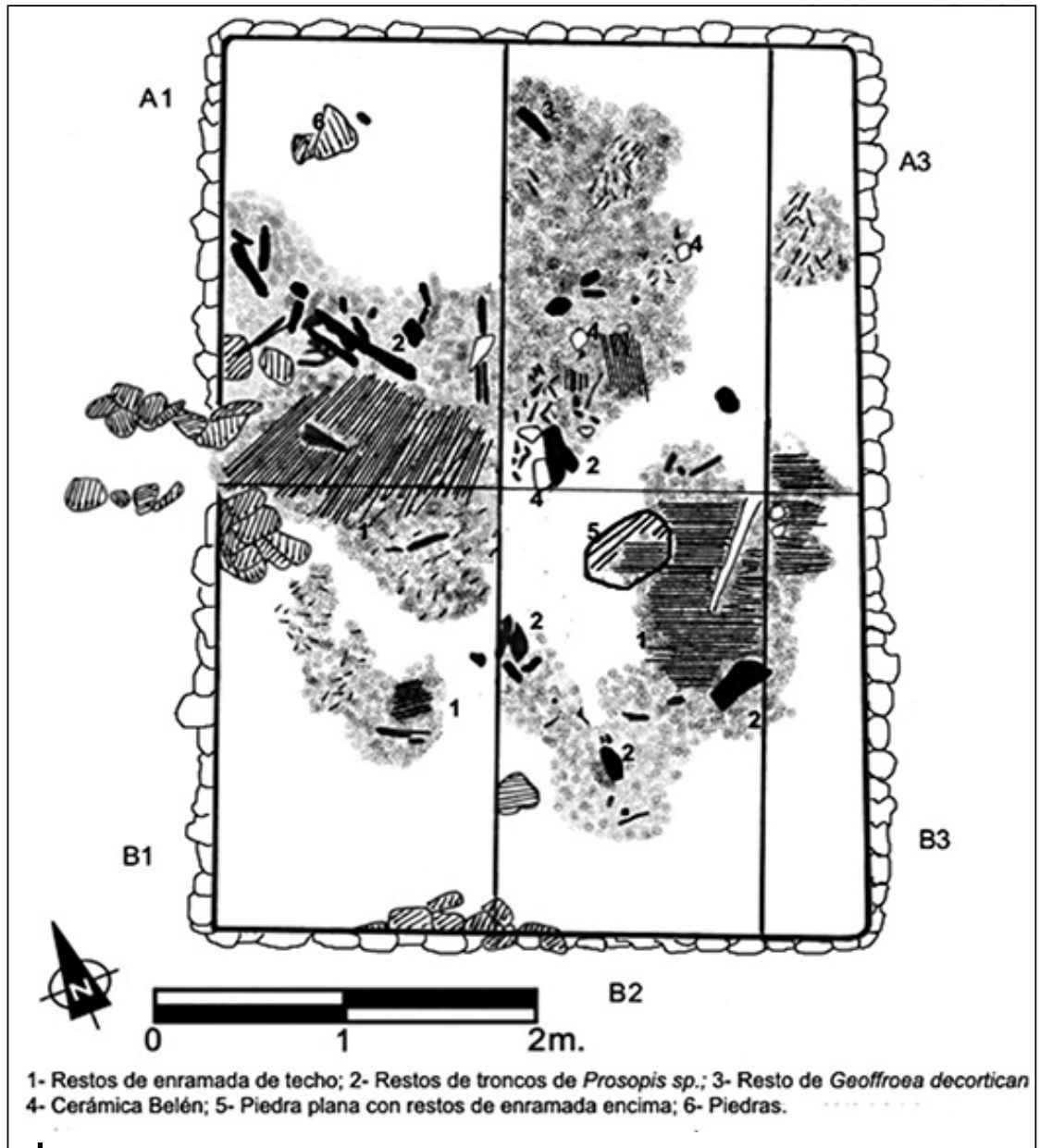

Figura 6 - Plano de las excavaciones en Lajas Rojas 4

En la cuadrícula A2, a partir de los $30 \mathrm{~cm}$ y sobre la pared norte, se presenta una capa de restos correspondientes a la enramada. Entre los 50 y $60 \mathrm{~cm}$ de profundidad se evidencia una horqueta junto con restos de diversos materiales (cerámica y huesos ubicados por debajo de troncos pequeños).

En el sector correspondiente a la cuadrícula B1, desde los $50 \mathrm{~cm}$ y hasta los $70 \mathrm{~cm}$ de profundidad, se observa una capa de ceniza que se profundiza hacia el pasillo de acceso y restos de enramada del techo dispuestos irregularmente.

En la cuadrícula B2 a partir de los $45 \mathrm{~cm}$, debajo de un derrumbe de piedras que corresponden a la pared sur, se hallaron restos de cerámica Belén y fragmentos de material leñoso carbonizado correspondientes a un tramo de tronco y restos de enramada. Las concentraciones de carbón llegan hasta los $70 \mathrm{~cm}$ junto a un marlo también carbonizado, por debajo del cual se hallaron restos óseos. 
Entre los 50 y $60 \mathrm{~cm}$ de profundidad se distingue una raíz de Larrea sp. sin carbonizar, que parece haber atravesado el recinto.

Aún no se han realizado dataciones radiocarbónicas en el sitio, pero sus características constructivas y materiales recuperados permiten adscribirlo, por el momento, al Período de Desarrollos Regionales/Inka7.

\section{ANÁLISIS DE LOS MATERIALES LEÑOSOS RECUPERADOS}

Para poder determinar la filiación taxonómica de carbones o maderas arqueológicas, es necesario el conocimiento de la estructura anatómica de las especies actuales. Con tal fin se creó un herbario, una colección de preparados histológicos de las especies leñosas que crecen hoy en día en el área y una colección con las mismas especies carbonizadas. Asimismo, se trabajó con los materiales de la xiloteca de la Facultad de Ciencias Agrarias y Forestales de la UNLP, que proporciona un referente empírico más completo ya que los sitios podrían contener materiales leñosos que hubieran sido transportados desde lugares alejados.

Las muestras de carbón fueron analizadas por cuadrícula y nivel. En una primera etapa se separaron los fragmentos por ubicación, tipo de resto, tamaño, posible utilización, y tipo de carbonización (completa/ incompleta).

Se han estudiado un total de 12 troncos de entre 3 y $15 \mathrm{~cm}$ de diámetro, los cuales habrían sido utilizados como vigas mayores y menores y para la confección de postes de sostén, según se discute más adelante.

La recuperación de los macrorrestos vegetales se realizó mediante recolección manual y cribado en seco.

Los materiales fueron identificados a través de la observación con microscopio óptico y microscopio electrónico de barrido (MEB) por comparación de la estructura anatómica del xilema de las maderas arqueológicas con las actuales. Se observaron las secciones Transversal, Longitudinal Tangencial y Longitudinal Radial. Las características cualitativas son descriptas usando la IAWA List of Microscopic Features for Hardwood Identification (IAWA, 1989).

7 Se cuenta con un fechado radiocarbónico del sitio Lajas Rojas 2, ubicado en la misma terraza, a pocos metros de distancia (LP 1793), que arrojó un resultado de $320 \pm 60$, calibrado con dos sigmas (curva SHcal04 (McCormac et al., 2004) con el Programa Calib Rev 5.0.1) se ubica entre 1459 y 1675 cal. DC. Lo interpretamos dentro de la segunda mitad del siglo XV, al igual que Loma de Ichanga, dada la ausencia de evidencia hispana. 
Cuadro 3 - Caracteres diagnósticos observados en las muestras arqueológicas

\begin{tabular}{|c|c|c|c|c|c|c|c|}
\hline Taxón & Anillos & Porosidad & $\begin{array}{c}\text { Disposición } \\
\text { de poros }\end{array}$ & Parénquima & $\begin{array}{l}\text { Sistema } \\
\text { Radial }\end{array}$ & $\begin{array}{l}\text { Tipo de } \\
\text { radio }\end{array}$ & Otros rasgos \\
\hline $\begin{array}{l}\frac{2}{n} \\
\frac{n}{2} \\
0 \\
0 \\
0 \\
2\end{array}$ & $\begin{array}{l}\text { Demar- } \\
\text { cados }\end{array}$ & Subcircular & $\begin{array}{c}\text { Solitarios en } \\
\text { series radiales } \\
\text { cortas y } \\
\text { largas, } \\
\text { agrupa-dos }\end{array}$ & $\begin{array}{l}\text { Paratraqueal, } \\
\text { bandas } \\
\text { confluentes, } \\
\text { aliforme y } \\
\text { confluente } \\
\text { terminal }\end{array}$ & $\begin{array}{l}\text { Hetero- } \\
\text { celular } \\
\text { radios } \\
\text { pluriseriados }\end{array}$ & $\begin{array}{l}\text { Homo- } \\
\text { celular, } \\
\text { células } \\
\text { procum- } \\
\text { bentes }\end{array}$ & $\begin{array}{c}\text { Puntuaciones } \\
\text { areoladas, } \\
\text { ornadas. Pared } \\
\text { interna de vaso } \\
\text { con engrosa- } \\
\text { mientos } \\
\text { ornados }\end{array}$ \\
\hline 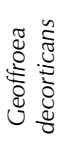 & $\begin{array}{c}\text { Demarca- } \\
\text { dos }\end{array}$ & $\begin{array}{c}\text { Subcircular } \\
\text { a difusa }\end{array}$ & $\begin{array}{c}\text { Solitarios y } \\
\text { series radiales } \\
\text { cortas }\end{array}$ & $\begin{array}{c}\text { Paratraqueal } \\
\text { en bandas } \\
\text { confluentes y } \\
\text { terminal }\end{array}$ & $\begin{array}{l}\text { Homoce- } \\
\text { lular } \\
\text { uniseriado }\end{array}$ & $\begin{array}{l}\text { Homoce- } \\
\text { lular } \\
\text { células } \\
\text { procum- } \\
\text { bentes }\end{array}$ & $\begin{array}{l}\text { Leño } \\
\text { estratificado }\end{array}$ \\
\hline
\end{tabular}

A continuación se proporciona la identificación de los materiales con sus respectivas medidas y su ubicación según cuadrícula y nivel.

Cuadro 4 - Lajas Rojas recinto 4

\begin{tabular}{|c|c|c|c|c|}
\hline Cuadrícula & Nivel & Material & Observaciones & $\begin{array}{l}\text { Identificación } \\
\text { Troncos }\end{array}$ \\
\hline $\mathrm{A} 1$ & $50-60$ & $\begin{array}{l}\text { Tronco y } \\
\text { enramada }\end{array}$ & $\begin{array}{l}\text { Largo } 56 \mathrm{~cm} \text { Diámetro; } \\
6 \mathrm{~cm} 11 \text { anillos de } \\
\text { crecimiento }\end{array}$ & Prosopis sp \\
\hline $\mathrm{A} 2$ & $50-60$ & $\begin{array}{l}\text { Tronco } \\
\text { (horqueta) } \\
\text { y enramada }\end{array}$ & $\begin{array}{l}\text { Largo } 20 \mathrm{~cm} ; \text { Diámetro } \\
8 \mathrm{~cm} ; 15 \text { anillos de } \\
\text { crecimiento }\end{array}$ & Prosopis sp \\
\hline $\mathrm{A} 2$ & $50-60$ & Tronco & $\begin{array}{l}\text { Largo } 15 \mathrm{~cm} ; \text { Diámetro } \\
5 \mathrm{~cm} ; 11 \text { anillos de } \\
\text { crecimiento }\end{array}$ & $\begin{array}{c}\text { Geoffroea } \\
\text { decorticans }\end{array}$ \\
\hline B2 & $50-60$ & Tronco & $\begin{array}{l}\text { Largo } 30 \mathrm{~cm} \text {; Diámetro } 8 \\
\mathrm{~cm}\end{array}$ & Prosopis sp \\
\hline B2 & $50-60$ & Tronco & $\begin{array}{l}\text { Largo } 17 \mathrm{~cm} \text {; Diámetro } 9 \\
\mathrm{~cm}\end{array}$ & Prosopis sp \\
\hline B2 & $50-60$ & Tronco & $\begin{array}{l}\text { Largo } 13 \mathrm{~cm} \text {; Diámetro } 7 \\
\mathrm{~cm}\end{array}$ & Prosopis sp \\
\hline
\end{tabular}


Cuadro 5 - Loma de Ichanga recinto 6

\begin{tabular}{|c|c|c|c|c|}
\hline Cuadrícula & Nivel & Material & Observaciones & $\begin{array}{l}\text { Identificación } \\
\text { Troncos }\end{array}$ \\
\hline $\begin{array}{l}\text { A1 (ángulo } \\
\text { con A2, B1 } \\
\text { y B2) }\end{array}$ & $60-70$ & Tronco & $\begin{array}{l}\text { Largo: } 22 \mathrm{~cm} \text {; Diám: } \\
7 \mathrm{~cm} ; 13 \text { anillos de } \\
\text { crecimiento; conserva } \\
\text { corteza y médula }\end{array}$ & Geoffrea decorticans \\
\hline B1 & $\begin{array}{l}40-50 \\
\text { (pared S) }\end{array}$ & $\begin{array}{lr}\text { Tronco } & y \\
\text { marlos } & \text { de } \\
\text { maíz } & \end{array}$ & $\begin{array}{l}\text { Largo: } 14 \mathrm{~cm} \text {; Diám: } \\
12 \mathrm{~cm} \text {; por debajo } 3 \\
\text { marlos de maíz }\end{array}$ & Prosopis sp. \\
\hline B1 & $\begin{array}{l}\text { 50-60 } \\
\text { (pared } \\
\text { W) }\end{array}$ & \begin{tabular}{|l|} 
Tronco \\
y concentra- \\
ciones de \\
marlos \\
de maíz \\
\end{tabular} & $\begin{array}{l}\text { Largo: } 31 \mathrm{~cm} \text {; Diám: } \\
15 \mathrm{~cm} ; 48 \text { anillos de } \\
\text { crecimiento; conserva } \\
\text { corteza y médula }\end{array}$ & Prosopis sp. \\
\hline B2 & $\begin{array}{l}40-50 \\
\text { (pared E) }\end{array}$ & Tronco & $\begin{array}{l}\text { Largo: } 14 \mathrm{~cm} \text {; Diám: } \\
7 \mathrm{~cm} ; 16 \text { anillos de } \\
\text { crecimiento }\end{array}$ & Prosopis sp. \\
\hline \multirow[t]{2}{*}{ B2 } & \multirow[t]{2}{*}{$60-70$} & $\begin{array}{l}\text { Tronco sobre } \\
\text { vasija }\end{array}$ & $\begin{array}{l}\text { Largo: } 41 \mathrm{~cm} \text {; Diám: } \\
9 \mathrm{~cm} ; 23 \text { anillos de } \\
\text { crecimiento }\end{array}$ & Prosopis sp. \\
\hline & & $\begin{array}{l}\text { Tronco sobre } \\
\text { vasija }\end{array}$ & $\begin{array}{l}\text { Largo: } 38 \mathrm{~cm} \text {; Diám: } \\
6 \mathrm{~cm}\end{array}$ & Prosopis sp. \\
\hline
\end{tabular}

\section{RESULTADOS Y DISCUSIÓN SOBRE EL MATERIAL ANTRACOLÓGICO}

El presente estudio fue posible gracias a las buenas condiciones de conservación de los restos forestales, como consecuencia de incendios. A ello debemos sumar la aplicación de una metodología sistemática de recuperación de carbones en la que se han combinado diversos procedimientos que han permitido interpretar y diferenciar los distintos restos procedentes de estructuras constructivas.

Respecto de los recursos utilizados en la construcción se ha determinado que en todos los casos se trata de maderas locales, observándose una mayor frecuencia del género Prosopis, seguido de Geoffroea decorticans (fig. 7).

En base a los registros arqueológicos y su comparación con la información etnográfica (Valencia et al., 2010; Valencia et al., 2009; Marconetto \& Mors, 2010; Marconetto \& Gordillo, 2008), se presume que la construcción de las estructuras requirió de troncos de distintos diámetros, de acuerdo a la función que debieran cumplir, ya fueran postes de sostén, vigas o enramada, sobre los cuales se ubicaba la torta del techo. 
Las características y disposición de los hallazgos nos hacen pensar que las técnicas constructivas pudieron ser similares a las que se usan en el presente en casas tradicionales, más allá de que actualmente se registra el uso de otros materiales leñosos de la zona, que fueron introducidos con posterioridad a la conquista española. Por otra parte, investigaciones sobre la reconstrucción de la vegetación de la zona, han puesto de manifiesto que las especies nativas actuales debieron estar presentes en el siglo XV (Capparelli \& Raffino, 1997).

Como se desprende de los datos expuestos en las tablas precedentes, los troncos presentaron diámetros de entre 3 y $15 \mathrm{~cm}$ poscarbonización. En la mayor parte de los casos, los restos correspondientes a Prosopis sp. exhibieron los diámetros mayores, los ejemplares de Geoffroea presentaron diámetros entre 5 y $7 \mathrm{~cm}$. El empleo diferencial de los géneros ha resultado en una función estructural específica para cada taxón, siendo mayoritariamente usado el género Prosopis para la confección de postes y Geoffroea para fabricar vigas (en la fig. 7 se exhiben los cortes de los materiales arqueológicos identificados).

En Lajas Rojas 4 no se hallaron evidencias de postes de sostén en los extremos del recinto; sin embargo, tomando como base de comparación las modalidades

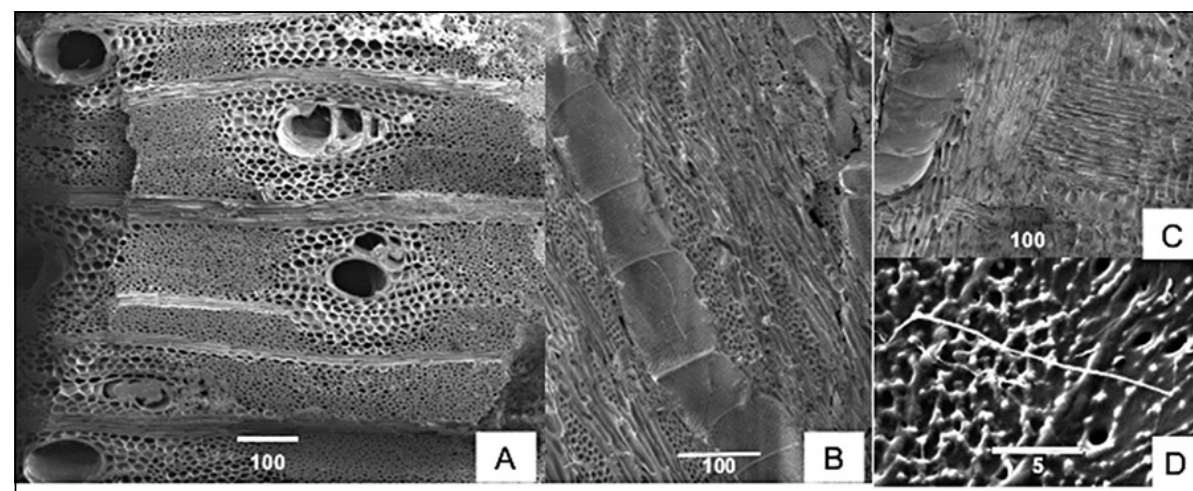

Prosopis sp. A- Corte transversal (CT). B- Corte Longitudinal Tangencial (CLTg). C-Corte Longitudinal Radial (CLR). D. Engrosamientos ornados en la pared interna del vaso. Escala en micrones.

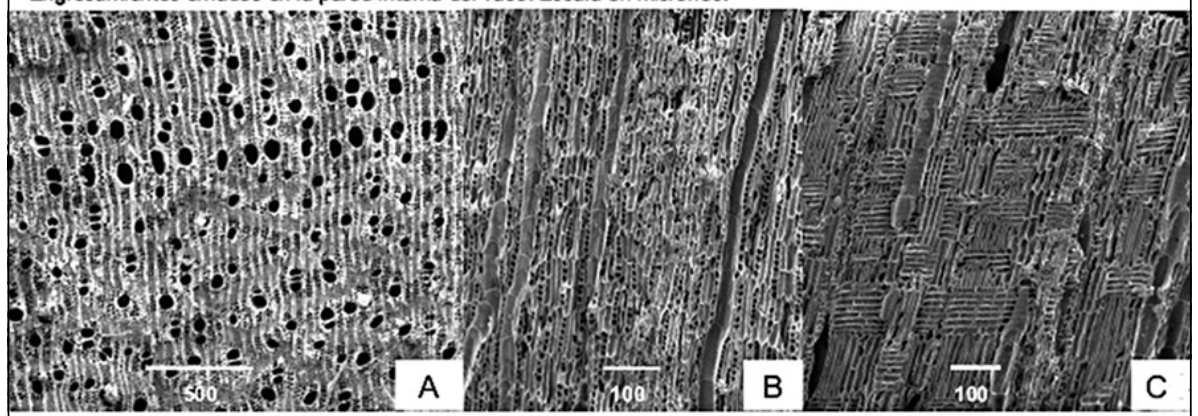

Geoffroea decorticans. A- Corte transversal (CT). B- Corte Longitudinal Tangencial (CLTg). C- Corte Loingitudinal Radial. Escala en micrones.

Figura 7 - Estructura anatómica de las especies identificadas 
constructivas tradicionales ya descritas, es probable que los mismos estuvieran ubicados por fuera, en las esquinas de la estructura. En el centro de este recinto, a los $50 \mathrm{~cm}$ de profundidad, se recuperó la parte superior de una horqueta. La misma fue identificada como Prosopis sp., y se estima, por su posición, que habría correspondido a un poste central ubicado dentro de la estructura. El resto de los troncos hallados en la misma, cuyos diámetros oscilan entre 5 y $9 \mathrm{~cm}$, fueron identificados en su mayoría como pertenecientes al género Prosopis y uno de ellos a Geoffroea. Inferimos, en base a sus dimensiones, ubicación y relaciones contextuales, que habrían correspondido a vigas mayores y menores que cumplían una función estructural en el sostén de la enramada.

En el caso de Loma de Ichanga, el análisis de los materiales recuperados permite suponer la existencia de postes de sostén en los cuatro extremos del recinto sobre los que se apoyaron vigas mayores para soportar la enramada y un poste central evidenciado por los dos pequeños círculos revestidos en piedras, que se interpretaron como agujeros para su colocación. Al respecto entendemos que el poste central habría sido removido con preexistencia al evento de incendio, ya que dentro del agujero no se hallaron evidencias de poste quemado.

También se recuperó abundante material correspondiente a la enramada y torta de techo, que se encuentra en proceso de análisis.

Por otra parte, es importante considerar el estado sanitario de las maderas previo a su carbonización. Los estudios sobre actividades de xilófagos8 indican que estos atacan la madera en su estado natural, cuando el árbol está en pie, produciendo daños considerables tanto en albura como en duramen (Florentino et al., 1997), mientras que esto no sucede con la madera carbonizada. En tal sentido, cabe señalar que el total de los materiales exhumados en ambos recintos presentaban carbonización completa y buenas condiciones sanitarias, atestiguadas por la ausencia de galerías de insectos.

Otro dato relevante, que relacionamos con el estado sanitario, consiste en el tipo de carbonización que presentan los materiales. En los sitios analizados encontramos que los restos exhumados exhiben carbonización completa y ausencia de galerías. Hemos podido contrastar esta situación con la de otros sitios de la zona, que se tratan con más detalle en el presente texto, lo cual nos permitió identificar diferencias en el registro con respecto al momento en que se produjeron los incendios.

\section{ALGUNAS CONSIDERACIONES SOBRE EL ABANDONO DE SITIOS}

Entre las primeras caracterizaciones exhaustivas sobre procesos de abandono se cuenta el trabajo de Schiffer (1987), en el cual vincula el abandono de sitios

8 En relación a las plagas forestales que perjudican a los ecosistemas nativos del Parque Chaqueño, Florentino y colaboradores (1997) mencionan las siguientes: Criodion angustatum Buquet; Torneutes pallidipennis Reich; Megacyllene spinífera Newman cuyos hospedantes pertenecen al género Prosopis sp.; los hospedantes de Oncíderes saga Dalman son Acacia sp. y Prosopis sp. 
con un conjunto de procesos que producen el depósito de artefactos, otorgando particular relevancia a los que caracteriza como desechos de facto. La cantidad y variabilidad de los desechos de facto están condicionadas por las características del abandono —rápido/lento; planificado/no planificado-. Schiffer propone establecer diferencias a nivel intrasitio y entre asentamientos, a fin de dilucidar cómo y por qué se produce la variabilidad entre estos depósitos (1987: 89).

El trabajo de Stevenson en Yukon fue pionero en el estudio de la producción de desechos de facto, en el cual establece que «... few artifacts and features will be found in processes of manufacture, use or maintenance on sites abandoned under normal or planned conditions...» (1982: 24). Por el contrario, cuando el abandono se produce en forma muy rápida, sin tiempo de planificación previa, se suelen encontrar desechos de facto en abundancia sobre los pisos (Chase \& Chase, 2000).

Los estudios más modernos sobre abandono de sitios han tenido su mayor desarrollo en el análisis de yacimientos del sudoeste de Estados Unidos y en Mesoamérica.

Dichos estudios han utilizado, como criterio principal para su identificación, la suspensión de una evidencia material de ocupación, que se apreciaba anteriormente en un mismo espacio. En general, se han desarrollado dentro de un marco de reflexión sobre la decadencia o el colapso de sociedades complejas, a partir de observaciones que indicaban la ausencia de materiales atribuibles a fases posteriores o la detección de «anomalías», tales como huellas de incendios, de catástrofes, de violencia, etc. (Darras, 2003). No obstante, la detección de las evidencias de abandono, así como la resolución de su escala (local, regional) constituyen problemáticas poco tratadas, a las cuales se puede aportar a través del estudio de materiales antracológicos.

En varias contribuciones se han señalado evidencias que apuntan al reconocimiento y caracterización de diversos contextos de abandono. En tal sentido, cuando se encuentran pocos o ningún desecho de facto en una estructura, se asume que los ítems fueron trasladados por los habitantes de los lugares abandonados. En estos casos se suele inferir que el abandono fue planificado y gradual, que la distancia al nuevo lugar de habitación era corta y/o que no se anticipaba retornar (Stevenson, 1982; Varien, 1999; Wilshusen, 1986). Por el contrario, cuando se encuentran grandes cantidades de desechos de facto las interpretaciones apuntan a que los mismos pudieron ser dejados porque el abandono no fue planificado, porque la distancia al siguiente destino era demasiado grande para trasladarlos, y/o porque se pensaba volver (Schlanger \& Wilshusen, 1996).

Si el abandono de una estructura se realiza cuando otras estructuras del mismo sitio aún están habitadas, existe la posibilidad de que sea utilizada para descartar basura en su interior, por lo cual en estas ocasiones, no se suele hallar vasijas completas o reconstruibles, sino fragmentos cerámicos no remontables dentro del relleno (Stevenson, 1982; Triadan, 1997).

Schlanger \& Wilshusen (1996) formulan cuatro estrategias de abandono de estructuras diferenciadas por la distancia de movimiento — corta o larga distancia - y la expectativa de retorno — con o sin retorno esperado—-, basadas en 
las prácticas de abandono de los anasazi y describen los correlatos arqueológicos de esas prácticas, fundados en el tratamiento de los techos y los conjuntos de materiales sobre el piso de las estructuras.

Según estos autores, el tratamiento de techos es el indicador menos ambiguo para su interpretación y comprende tres modos diferentes: techumbres recuperadas, intactas o incendiadas intencionalmente.

Cuando se recuperan los postes de una estructura para su posterior uso y se deja que la techumbre colapse sobre el piso, en el perfil estratigráfico el depósito se ve como uniforme y masivo, con lentes de materia orgánica correspondientes a pequeñas estructuras del techo, desparramadas sobre el piso y llenando — si los hubiere-, los huecos que albergaban postes de sostén.

En caso de abandono de la estructura intacta, esta se deteriora y es rellenada por procesos naturales. El relleno no se presenta como en el caso anterior, como una unidad uniforme y masiva y si existe una ruptura estratigráfica, la misma corresponde a procesos naturales geomorfológicos o de formación del suelo.

En el caso de techos incendiados intencionalmente, los autores han observado, en perfil estratigráfico, una capa de unos 20 a $40 \mathrm{~cm}$ de techo quemado, en contacto directo con el piso, algunos sectores de las paredes y del piso exhibían signos de oxidación y ausencia de basura. Esto ha sido interpretado como un movimiento de larga distancia, sin intención de retorno.

En relación con la propiedad y uso de estructuras y artefactos, se puede señalar que al incendiar una estructura, sus dueños se aseguran de que las mismas no podrán ser ocupadas por otros habitantes, que no serán destinadas a otras funciones y que si hubieran dejado objetos sobre el piso, los mismos no serán objeto de saqueo.

\section{EVIDENCIAS DE ABANDONO EN OTROS SITIOS EXCAVADOS EN EL VALLE DE HUALFÍN}

A continuación se comentarán los resultados de excavaciones en otros sitios del valle de Hualfín, en los cuales se han recuperado materiales forestales que presentan diversas características y modalidades de deposición, a fin de compararlos con los de Loma de Ichanga y Lajas Rojas 4.

Se refieren tareas realizadas en la localidad de La Ciénaga (Cerro Colorado y Lajas Rojas 2) y en la localidad de Azampay (Campo de Carrizal y Loma de los Antiguos).

En el recinto 48 del Cerro Colorado, Sempé \& Pérez Meroni (1988) exhumaron gran cantidad de troncos, restos de techumbre y marlos de maíz carbonizados, junto a una vasija adscripta al tipo Belén. Las autoras comentan que los materiales carbonizados conformaban un sector de aproximadamente $2 \mathrm{~m}$ de diámetro dentro del recinto.

En el denominado Sector Central se excavaron dos recintos asociados, denominados 35 y 36, el primero de ellos en forma parcial y el segundo en forma 
completa (Balesta \& García Mancuso, 2010). En el recinto 35 no se hallaron restos vegetales de ningún tipo. Dentro de la habitación 36, a partir de los 20 cm y hasta el piso, se hallaron restos vegetales carbonizados, interpretados como torta del techo, vigas y postes portantes, uno de ellos in situ. Los materiales fueron identificados como Prosopis sp. y Geoffroea decorticans (Valencia et al., 2010).

También sobre el piso se recuperó una tinaja Belén Negro sobre Rojo casi completa y fragmentos de cerámica ordinaria con la superficie carbonizada. Además, se halló un fragmento de tubo cerámico con engobe blanco y decoración negra en damero; una bola de material volcánico, de 35 mm de diámetro, con incisiones y un fragmento de «cuchillo semilunar», adjudicado a contextos preinkaicos tardíos (C. Angiorama, comunicación personal). Por otra parte, se encontraron dos estructuras funerarias que contenían sendas urnas tapadas con dos cuencos, de las cuales se exhumaron tres esqueletos infantiles (Balesta \& García Mancuso, 2010).

Al pie del Cerro Colorado se excavó Lajas Rojas 2, de similares condiciones constructivas a Lajas Rojas 4. En el recinto se recuperaron pequeños fragmentos de carbón dispersos, pero no se registraron restos de techumbre. Sobre el piso se halló una cubeta con ceniza; en sus cercanías habían fragmentos cerámicos ordinarios y del tipo Belén y restos arqueofaunísticos. En esta estructura se halló solo un tronco carbonizado, que se identificó como Prosopis sp. y que se encontraba en buen estado sanitario (Valencia et al., 2007).

El sitio Campo de Carrizal de la localidad de Azampay, se halla a unos $21 \mathrm{~km}$ al NO de la Loma de Ichanga. Corresponde a cinco núcleos de recintos agrupados de a dos o tres, que se ubican sobre niveles de terrazas artificiales, en tres espolones que bajan de los cerros. Los niveles de terrazas conforman una serie de andenes de cultivo y obras hidráulicas — varias acequias y un estanque-, construidas para desarrollar tareas agrícolas. En las excavaciones llevadas a cabo en cinco recintos completos y dos en forma parcial, se halló abundante cerámica, objetos de hueso, piedra y metal. Entre los restos maderables se destacan tres postes y una pala.

En el recinto 2 del Espolón 2 se halló un poste desecado, a partir de los 70 cm y hasta los $90 \mathrm{~cm}$, en que se encontraba el piso. El poste se hallaba parado, apoyado entre dos rocas graníticas; se recuperaron fragmentos del mismo en una línea de aproximadamente $2 \mathrm{~m}$ en dirección SO, sobre el piso. Se cree que puede haber alcanzado unos 2,35 m; fue determinado como Prosopis chilensis e interpretado como poste de sostén del techo (Capparelli et al., 2003).

El Recinto 1 del Espolón 3 fue excavado parcialmente; en él se hallaron dos postes y una pala de madera, que estaba completa pero invadida por raíces y atacada por xilófagos. Los postes comenzaron a manifestarse a partir de los $40 \mathrm{~cm}$ de profundidad, hasta los $90 \mathrm{~cm}$, en que se encontró el piso. Uno de ellos estaba totalmente carbonizado y el otro se hallaba semicarbonizado y en avanzado estado de deterioro por la acción de xilófagos. Ambos postes fueron interpretados con una función para sostén de techumbre y al igual que la pala, fueron identificados como pertenecientes al género Prosopis; uno de ellos a Prosopis chilensis (Valencia et al., 2009; Zagorodny et al., 2007). 
También en la localidad de Azampay se encuentra Loma de los Antiguos, un sitio fortificado, ubicado a $2 \mathrm{~km}$ al SO de Campo de Carrizal, que consta de 45 estructuras, de las cuales se ha excavado un $52 \%$.

En la década de 1950 se trabajó en la habitación 45 que presentó un fogón circular, grandes ollas rústicas fragmentadas y restos de vegetales carbonizados en el suelo. Dichos restos fueron identificados como trozos de legumbres de algarrobo Prosopis alba y conglomerados y semillas de maní Arachis hypogaea. Se ha interpretado que «los grandes cántaros contuvieron maníes pelados y maíz. Al incendiarse el techo de la habitación, éste aplastó los cántaros. El espesor del techo, de ramas y paja, produjo una combustión intensa, con el consiguiente quemado parcial y carbonización de lo que estaba en el piso de la habitación» (González \& Pérez, 1968: 225).

A partir de la década de 1990 se realizaron tareas que proveyeron nuevas evidencias; en el recinto 21 se recuperaron nueve troncos, pertenecientes también al género Prosopis. Los mismos corresponderían a varios posibles postes de sostén del techo y vigas, con distintos estados de conservación que comprenden desde una carbonización incompleta, con presencia de galerías de insectos, hasta la carbonización total. El resto de los materiales antracológicos está representado por enramada chica y mediana y restos de torta del techo. Los materiales que presentaban combustión incompleta se hallaban atacados por xilófagos. La disposición de los postes en el recinto era asimétrica, lo que hace suponer que al momento del abandono algunos postes habrían sido dejados en su sitio, mientras que otros se habrían retirado.

Los sitios reseñados fueron fechados, obteniéndose rangos que los ubican mayoritariamente a partir del siglo XV (Balesta et al., 2011).

De acuerdo a los resultados de las excavaciones comentadas, se puede sintetizar que en varios recintos no se hallaron restos antracológicos, por lo cual se presume que aquellos que hubieran estado techados fueron abandonados y los restos forestales decayeron hasta desaparecer. En los recintos en que se recuperaron restos maderables, se establecieron diferencias, según su cantidad, deposición, carbonización y estado sanitario.

En Lajas Rojas 2 no se conservaron restos de techo, solo se recuperó un fragmento de madera de Prosopis sp. y hay evidencias de una cubeta con ceniza — posible fogón-, interpretándose como un abandono con posterior decadencia y desaparición de los restos forestales.

En Campo de Carrizal los restos de techo son escasos y se habrían deteriorado por acción natural, exhibiendo un estado sanitario deficiente. En un caso, se atestigua un incendio posterior al abandono, sobre lo que quedaba aún en pie y en donde los materiales que se quemaron cesaron de ser atacados por insectos.

Cerro Colorado (recintos 48 y 36) y Loma de los Antiguos (recinto 45) exhiben incendios con materiales depositados en forma masiva, de lo que parecen haber sido techos enteros, en sucesión estratigráfica, con evidencias de todos los componentes colapsados por encima de escasos materiales que se hallaban sobre el piso. 
El caso del recinto 21 de Loma de los Antiguos es más difícil de interpretar. Si bien la cantidad de materiales de techumbre es importante, es menor que en Cerro Colorado, Lajas Rojas 4 e Ichanga, pero probablemente el incendio se produjo cuando aún quedaba gran parte del techo en pie.

\section{INTERPRETACIÓN DE LOS RESULTADOS}

El análisis del registro antracológico de los sitios considerados nos ha permitido un acercamiento a las formas de aprovechamiento de los recursos forestales en el pasado que, unida a las características contextuales vinculadas al abandono, contribuye al conocimiento de la gestión del paisaje a partir del siglo XV en el valle de Hualfín. Los resultados indican la utilización de recursos forestales autóctonos en la construcción de estructuras habitacionales.

En los casos analizados, el empleo claramente mayoritario de Prosopis puede interpretarse como una selección y uso en favor de las especies de este género, que fueron empleadas principalmente para la confección de postes de sostén y vigas que portaban mayor peso mientras que Geoffroea se utilizó para vigas de menor porte.

Nuestras evidencias se podrían explicar en términos de un comportamiento selectivo a favor de ciertas especies, relacionado al conocimiento empírico sobre las materias primas empleadas, de modo que la selección de maderas para el cumplimiento de funciones puntuales estaría ligada no solo a la oferta sino también a sus propiedades y características anatómicas. En tal sentido, Bulnesia retama es tan dura como Prosopis, pero alcanza menor altura y por lo tanto resulta menos apropiada para construir postes de sostén, mientras que Acacia visco es más blanda y menos resistente a la humedad.

No obstante, no debemos dejar de considerar la posibilidad de que las representaciones de estas especies, en distintas medidas, se deban a sesgos en el registro por diferencias de conservación (Marconetto, 2008; Valencia et al., 2010).

Otra cuestión importante vinculada con esta selección puede estar marcada por características no materiales atribuidas a los recursos; las dimensiones simbólicas pueden tener gran relevancia a la hora de seleccionar especies, existiendo aspectos vinculados tanto a tabúes como a valores positivos. Los algarrobos han sido usados en el NOA por poblaciones antiguas y continúan siendo utilizados en la actualidad. Se aprovechan, como se ha señalado, en la construcción y combustión y también para producir alimentos y medicinas (Roig, 1993; 2001). Teniendo en cuenta la información etnográfico-lingüística, un aspecto que pone de manifiesto la importancia del Prosopis en el NOA, es que sus habitantes lo llaman «el árbol». Una variable trascendente vinculada con la selección de las maderas para la construcción es su estado sanitario. A partir de los resultados obtenidos en el presente se ha evidenciado la utilización de maderas sanas. Esta característica permite inferir que al conocimiento empírico de los grupos sobre las materias primas y la selección de ejemplares sanos para la construcción, se sumaban 
actividades de reparación mediante la incorporación de nuevas maderas a la estructura durante su uso, lo que se ha denominado como «prácticas de mantenimiento» (Marconetto, 2008).

Con respecto a la interpretación de la modalidad de abandono, hemos tomado indicios basados en la literatura producida a tal efecto que comentamos ut supra; los mismos consisten en el estado y disposición de los techos, la cantidad, características y ubicación de los restos materiales sobre los pisos — dentro de los cuales se consideran específicamente los restos antracológicos- y el estado sanitario de las maderas.

En el recinto 6 de Loma de Ichanga y en Lajas Rojas 4, los pisos se presentan limpios, sin basura y con baja densidad —en comparación con otros recintos excavados en el Valle--, de desechos de facto. En el caso de Loma de Ichanga, al igual que en el recinto 36 del Cerro Colorado, se han recuperado artefactos significativos, por sus características y baja recurrencia en sitios, tales como una figurina, una vasija Sanagasta, una bola de piedra incisa, un objeto de metal y dos entierros. Cuando se abandona un sitio/estructura de forma planificada, se traslada la mayor parte de los artefactos que aún pueden ser usados en otro destino; esto es parte de la planificación del abandono. En caso de dejarse algunos objetos, estos suelen ser los que ya no pueden utilizarse o algún objeto significativo, que deje testimonio de la identidad de sus ocupantes (Chase \& Chase, 1998).

En cuanto a los techos, se presentan incendiados en forma completa, lo cual se atestigua por la presencia de maderas correspondientes a los postes de sostén y vigas como así también de restos de enramada y torta de techo, hallados en posición estratigráfica. Tal como hemos descrito, los materiales carbonizados se muestran, en el perfil estratigráfico, como depósitos de unos $40 \mathrm{~cm}$ de espesor, que contienen parte del enramado y torta del techo, bajo los cuales se hallaron restos de vigas y postes. En el caso de Loma de Ichanga, la falta del poste central y la presencia de hoyos para sostenerlo atestiguan su retiro. En Lajas Rojas 4, la horqueta recuperada puede representar un poste central de sostén, mientras que la ausencia del resto de los postes puede deberse a que se colocaran por fuera $y / 0$ se hayan retirado intencionalmente.

La ausencia de daños producidos por actividad de xilófagos en las maderas estudiadas sustenta la idea de que el incendio sucedió inmediatamente después del abandono de los sitios, ya que como se observa etnográficamente, un hiato entre el abandono y el incendio habría implicado la presencia de abundantes galerías (Marconetto, 2008).

Las evidencias descriptas nos conducen a proponer que en ambos casos ocurrió un incendio intencional vinculado a un abandono planificado de las habitaciones. El contexto detallado nos lleva a hipotetizar que los postes retirados podrían ser reutilizados en la construcción de nuevas estructuras en otros destinos (Schlanger \& Wilshusen, 1996) o usados como inflamable. Otra alternativa sería que su remoción se realizara para alimentar la combustión de las estructuras al momento del abandono (Wilshusen, 1986). 
En estudios previos, focalizados en la dimensión espacial del paisaje para el área analizada, hemos mostrado distintos aspectos sociopolíticos de la sociedad Belén, reflejando una construcción del paisaje que privilegia los elementos vinculados con situaciones de conflicto (Balesta \& Wynveldt, 2010; Wynveldt \& Balesta, 2009). En tal sentido, consideramos ilustrativos los registros hallados en varios sitios del valle de Hualfín, que exhiben incendios masivos, ausencia de basureros, limpieza en los pisos de las habitaciones, escasas vasijas cerámicas sobre dichos pisos y remoción de postes. A ellos se suman hallazgos de puntas de proyectil de obsidiana y el entierro de un individuo sin cabeza en Loma de los Antiguos y diversas inhumaciones de adultos con sus cabezas separadas de los cuerpos (Balesta et al., 2011).

Dichas cuestiones nos han llevado a pensar en un abandono planificado, con alcance a varias estructuras de sitios contemporáneos, producido como consecuencia de conflictos, que podrían corresponder tanto a la existencia de algunos privilegios dentro de la propia sociedad Belén, como a la presencia del Tawantinsuyu en el valle (Wynveldt \& Balesta, 2009; Balesta et al., 2011).

\section{Referencias citadas}

ALOSILLA, J., IUCCI, M. E. \& VALENCIA, M. C., 2006 - Procesos naturales y culturales que inciden en el estado de conservación de los sitios de la Localidad arqueológica de La Ciénaga. Dpto. de Belén. Pcia. de Catamarca. La Zaranda de Ideas, Vol. 2: 51-66.

BALESTA, B. \& GARCÍA MANCUSO, R., 2010 - Entierros infantiles en una habitación del Cerro Colorado de La Ciénaga de Abajo. In: Aldeas protegidas, conflicto y abandono. Investigaciones arqueológicas en La Ciénaga (B. Balesta \& N. Zagorodny, eds.): 241-276; La Plata: Ediciones Al Margen.

BALESTA, B. \& WYNVELDT, F., 2010 - La Loma de Ichanga: visibilidad, defensibilidad y abandono en el Valle de Hualfín (Depto. de Belén, Prov. de Catamarca, Argentina). Revista Española de Antropología Americana, Vol. 40 (1): 53-71; Madrid.

BALESTA, B. \& ZAGORODNY, N. (eds.), 2010 - Pueblos protegidos, conflicto y abandono. Excavaciones Arqueológicas en La Ciénaga, 325 pp.; La Plata: Ediciones Al Margen.

BALESTA, B., VALENCIA, C. \& FLORES, M., 2005 - Historia local y pasado prehispánico en Azampay (Catamarca. Argentina). «Actas del I Congreso de la Asociación Latinoamericana de Antropología». Formato CD.

BALESTA, B., ZAGORODNY, N. \& WYNVELDT, F., 2011 - La configuración del paisaje Belén. Relaciones de la Sociedad Argentina de Antropología, XXXVI: 149-175; Buenos Aires.

CABRERA, A., 1976 - Regiones Fitogeográficas Argentinas. Enciclopedia Argentina de Agricultura y Jardinería, 85 pp.; Buenos Aires: Acme. Segunda Edición.

CAPPARELLI, A. \& RAFFINO, R., 1997 - La Etnobotánica de «El Shincal» (Catamarca) y su importancia para la arqueología I: Recursos combustibles y madereros. Parodiana, 10 (1-2): 181-188. 
CAPPARELLI, A., ZAGORODNY, N. \& BALESTA, B., 2003 - Wood remains from Andean Argentina: the use of Prosopis sp. L. in hut construction. Journal of Ethnobiology, Volume 23 n. ${ }^{\circ}$ 1: 143-154; Spring-summer.

CHASE, A. \& CHASE, D., 1998 - Scale and Intensity in Classic Period Maya Agriculture: Terracing and Settlement at the "Garden City" of Caracol, Belize. Culture and Agriculture, 20: 60-77.

CHASE, A. \& CHASE, D., 2000 - Inferences about Abandonment: Maya Household Archaeology and Caracol, Belize. Mayab, 13: 67-77.

DARRAS, V., 2003 - La arqueología del abandono: algunos apuntes desde Mesoamérica. Trace, 43: 11-24.

FLORENTINO, D. C., DIODATO, L., NOTARIO, A. \& CASTRESANA., L., 1997 - Biología y evaluación de los daños producidos por Criodion angustatum Buquet y Torneutes pallidipennis Reich (Coleoptera: Cerambycidae) en Prosopis nigra (Gris.) Hieron. Boletín de sanidad vegetal. Plagas, 23: 273-281; Santiago del Estero (Argentina).

GONZÁlEZ, A. R., 1979 - Dinámica Cultural del N. O. Argentino. Evolución e Historia en las culturas del N. O. argentino. Antiquitas. Boletín de la Asociación Amiga del Instituto de Arqueología. Facultad de Historia y Letras de la Universidad del Salvador, 28-29: 1-15.

GONZÁlEZ, A. R. \& PÉREZ, J. A., 1968 - Una nota sobre etnobotánica del N. O. Argentino. In: Actas y Memorias. XXXVII Congreso Internacional de Americanistas. Vol. II: 209234; Buenos Aires.

IAWA, 1989 - IAWA list of microscopic features for hardwood identification. IAWA Bulletin n.s., 10: 219-332.

IFONA, 1985 - Anuario de Estadísticas Forestales; Buenos Aires: Instituto Forestal Nacional. Ministerio de Economía de la Nación.

MARCONETTO, B., 2008 - Linnaeus en el Ambato. El uso de la clasificación taxonómica. In: Arqueobotánica y Teoría Arqueológica. Discusiones desde Sudamérica (M. Giovannetti, V. Lema \& S. Archila, eds.): 143-166; Bogotá: Uniandes.

MARCONETTO, B. \& GORDILLO, I., 2008 - Los techos del vecino: Análisis antracológico de restos de construcción carbonizados de los sitios "Iglesia de los Indios" y "Piedras Blancas" (Catamarca). Darwiniana, 46 (2): 213-226.

MARCONETTO, B. \& MORS, B., 2010 - Casas en el Monte y el Monte en la Casa. Análisis Antracológico de las Estructuras de Construcción del Valle de Ambato. Catamarca. Argentina. In: Actas del XVII Congreso Nacional de Arqueología Chilena, tomo 2: 1237-1246; Valdivia.

MCCORMAC, F., HOGG, A., BLACKWELL, P., BUCK, C., HIGHAM, T. \& REIMER, P., 2004 - SHCal04 Southern Hemisphere Calibration 0 - 11.0 cal kyr BP. Radiocarbon, 46: 1087-1092.

MORLANS, C., 1995 - Regiones naturales de Catamarca: Provincias geológicas y Provincias fitogeográficas. Revista de Ciencia y Técnica. Universidad de Catamarca, 2 (2): 2025; Catamarca.

NIELSEN, A., 2002 - Asentamiento, conflictos y cambio social en el altiplano de Lípez (Potosí. Bolivia). Revista Española de Antropología Americana, 32: 179-205.

NÚÑEZ REGUEIRO, V., 1974 - Conceptos instrumentales y marco teórico en relación al análisis del desarrollo cultural del noroeste argentino. Revista del Instituto de Antropología de la Universidad Nacional de Córdoba, Vol. 5: 169-190.

ROIG, F. A., 1993 - Aportes a la etnobotánica del género Prosopis. In: Contribuciones Mendocinas a la Quinta Reunión Regional para América Latina y el Caribe de la 
Red de Forestación del CIID. Conservación y Mejoramiento de Especies del Género Prosopis: 99-119; Mendoza, Argentina: IADIZA CRICYT, Ed.

ROIG, F. A., 2001 - Flora medicinal mendocina. Las plantas medicinales y aromáticas de la provincia de Mendoza (Argentina). (Aborígenes, exóticas espontáneas o naturalizadas y cultivadas), 300 pp.; Mendoza: EDIUNC.

ROTHHAMMER, F. \& SANTORO, C., 2001 - El desarrollo cultural en el Valle de Azapa, extremo Norte de Chile y su vinculación con los desplazamientos poblacionales altiplánicos. Latin American Antiquity, Vol. 12, n. ${ }^{\circ}$ 1: 59-66.

SCHLANGER, S. A. \& WILSHUSEN, R., 1996 - Local abandonments and regional conditions in the North American Southwest. In: Abandonment of settlements and regions (C. Cameron \& S. Tomka, eds.): 85-98; Nueva York: Cambridge University Press.

SCHIFFER, M., 1987 - Formation Processes of the Archaeological Record, 428 pp.; Utah: University of Utah Press.

SEMPÉ, M. C. \& PÉREZ MERONI, M., 1988 - Nuevo fechado para la cultura Belén, Catamarca. Su evaluación. In: Resúmenes de las ponencias del IX Congreso Nacional de Arqueología Argentina: 56; Buenos Aires: Universidad de Buenos Aires, Facultad de Filosofía y Letras.

STEVENSON, M., 1982 - Toward an understanding of site abandonment behavior: Evidence from Historic Mining Camps in the Southwest Yukon. Journal of Anthropological Archaeology, 1: 237-265.

TORTORELLI, L. A., 1956 - Maderas y Bosques Argentinos, 756 pp.; Buenos Aires: Editorial Acme.

TRIADAN, D., 1997 - Ceramic Commodities and Common Containers. Anthropological Papers of the University of Arizona, 61: 145; Tucson.

VALENCIA, M. C., FERNÁNDEZ, M. \& BARBERIS, C., 2010 - Evidencias de Incendios en el Registro Arqueológico de la Localidad de La Ciénaga. Valle de Hualfín. (Catamarca - Argentina). In: Pueblos protegidos, conflicto y abandono. Excavaciones Arqueológicas en La Ciénaga: 161-199; La Plata: Ediciones Al Margen.

VALENCIA, M. C., ZAGORODNY, N. \& RIVERA., S. M., 2009 - Análisis de Restos de Madera en el sitio Campo de Carrizal. Valle de Hualfín, Departamento de Belén, Catamarca. Darwiniana, 47 (2): 260-266.

VARIEN, M., 1999 - Sedentism and Mobility in a Social Landscape: Mesa Verde and Beyond, 336 pp.; Tucson: University of Arizona Press.

WILSHUSEN, R., 1986 - The Relationship Between Abandonment Mode and Ritual Use in Pueblo I Anasazi Protokivas. Journal of Field Archaeology, 13: 245-254.

WYNVELDT, F., 2007 - La estructura de diseño decorativo en la cerámica Belén (Noroeste argentino). Boletín del Museo Chileno de Arte Precolombino, Vol. 12 n. ${ }^{0}$ 2: 49-67; Santiago de Chile.

WYNVELDT, F. \& BALESTA, B., 2009 - Paisaje político y beligerancia en el valle de Hualfín (Catamarca. Argentina). Revista Antípoda, n. ${ }^{\circ}$ 8: 143-168; Colombia: Universidad de los Andes.

ZAGORODNY, N., RIVERA, S. \& VALENCIA, C., 2007 - Análisis antracológico de restos y objetos de madera del sitio Campo de Carrizal. In: Actas del XVI Congreso Nacional de Arqueología Argentina. Tomo I: 133-139; Jujuy. 